\title{
Extravasamento de líquido no mediastino e derrame pleural durante artroscopia de ombro: relato de caso"
}

\author{
Fluid leakage into the mediastinum and pleural effusion \\ during shoulder arthroscopy: a case report
}

\author{
Leandro Cardoso Gomide ${ }^{1}$, Celso Eduardo Ribeiro Gonçalves Santos ${ }^{1}$, Cleber Jesus Pereira ${ }^{1}$, \\ luiz Cláudio Coelho Carvalho', Sérgio Antônio Souza Queiroz', \\ Roberto da Cunha luciano ${ }^{1}$, Daniel Barros Pereira ${ }^{2}$
}

\section{RESUMO}

O presente trabalho tem o objetivo de apresentar uma rara, porém possível complicação respiratória durante uma artroscopia de ombro executada na posição de "cadeira de praia". Houve extravasamento de líquido para o mediastino durante o procedimento quando se usava a bomba de infusão, ocasionando dificuldade respiratória. $O$ tratamento foi conservador, com retardamento da extubação, internação em unidade de terapia intensiva, diuréticos e medidas de suporte. No quarto dia de pós-operatório, a paciente estava assintomática em relação a tal complicação.

Descritores - Artroscopia/efeitos adversos; Insuficiência respiratória/ etiologia; Ombro/cirurgia; Relatos de casos [Tipo de publicação]

\section{ABSTRACT}

This study is intended to present a rare but possible respiratory complication during a shoulder arthroscopy performed in the beach chair position. Fluid leaked into the mediastinum during the procedure when the infusion pump was being used, which caused respiratory difficulty.

* Trabalho realizado no Hospital Ortopédico Orthomedcenter - Uberlândia (MG), Brasil.

1. Ortopedistas do Hospital Orthomedcenter - Uberlândia (MG), Brasil.

2. Chefe do Serviço de Ortopedia do Hospital Orthomedcenter - Uberlândia (MG), Brasil.

Endereço para correspondência: Av. Rondon Pacheco, 555, Bairro Copacabana - 38400-242 - Uberlândia, MG. Tel.: (34) 3233-0555.

E-mail: leandro@ orthomedcenter.com.br

Recebido em 26/6/06. Aprovado para publicação em 14/8/07.

Copyright RBO2007
Treatment was conservative, with extubation delay, stay at the Intensive Care Unit, diuretic drugs, and support action. In the fourth postoperative day, the patient was asymptomatic regarding such complication.

Keywords - Arthroscopy/adverse effects; Respiratory insufficiency/ etiology; Shoulder/surgery; Case reports [Publication type]

\section{RELATO DO CASO}

C.S.M., 69 anos de idade, gênero feminino, portadora de lúpus eritematoso sistêmico (LES), usuária de prednisona $5 \mathrm{mg} /$ dia havia cerca de 20 anos, apresentava dor localizada no ombro direito com um ano de evolução, após queda. Ao exame físico do ombro, foi evidenciada amplitude de movimentação ativa normal, testes de Neer e Hawkins positivos, teste de Jobe positivo e ausência de sintomas na articulação acromioclavicular. Foi realizada ressonância magnética, a qual evidenciou rotura tendínea do músculo supra-espinal, na sua inserção. Havia substituição gordurosa grau 2 e os demais tendões não estavam rotos.

Não foi identificado nenhum problema clínico, com exceção do lúpus durante a visita pré-anestésica.

O procedimento foi realizado sob bloqueio de plexo braquial associado à anestesia geral. A paciente foi colocada em posição de "cadeira de praia". Durante a artroscopia, utilizouse bomba de infusão com pressão de $60 \mathrm{mmHg}$ e fluxo de 1,2L/min. Após 50 minutos de procedimento cirúrgico (término de sutura do manguito com duas âncoras), evidenciouse grande aumento de volume do ombro e região cervical. A saturação de $\mathrm{O}_{2}$ havia caído, nesse momento, para $82 \%$. Após três minutos, a paciente começou a apresentar cianose. Dian- 
te de tal situação, o anestesista pediu para que a cirurgia fosse interrompida imediatamente, a fim de colocar a paciente na posição supina, melhorando a oxigenação sanguínea, prevenindo lesões vasculares cerebrais. A pressão arterial mantevese normal durante todo o procedimento. Foram utilizadas também duas ampolas de furosemida, com o objetivo de facilitar a eliminação do líquido injetado, em excesso, pela bomba de infusão. Devido ao intenso edema, optou-se por não extubar a paciente, encaminhando-a à unidade de terapia intensiva (UTI).

Foi feita radiografia do tórax (figura 1), evidenciando-se compressão das vias aéreas por provável derrame no mediastino e derrame pleural à direita. Foi decidido somente manter as medidas de suporte, como oxigenação adequada e verificação dos dados vitais.

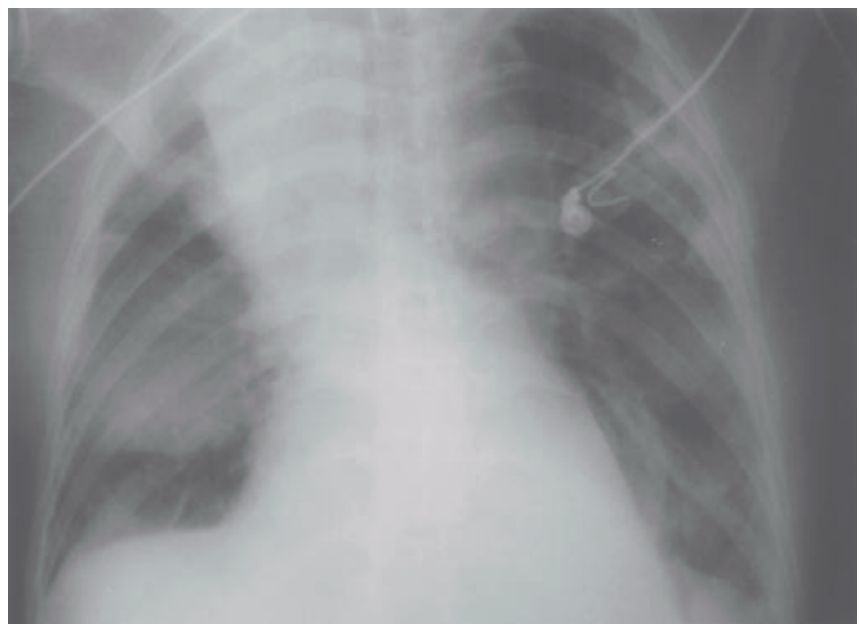

Figura 1 - Radiografia de tórax evidenciando derrame de líquido no mediastino e na pleura

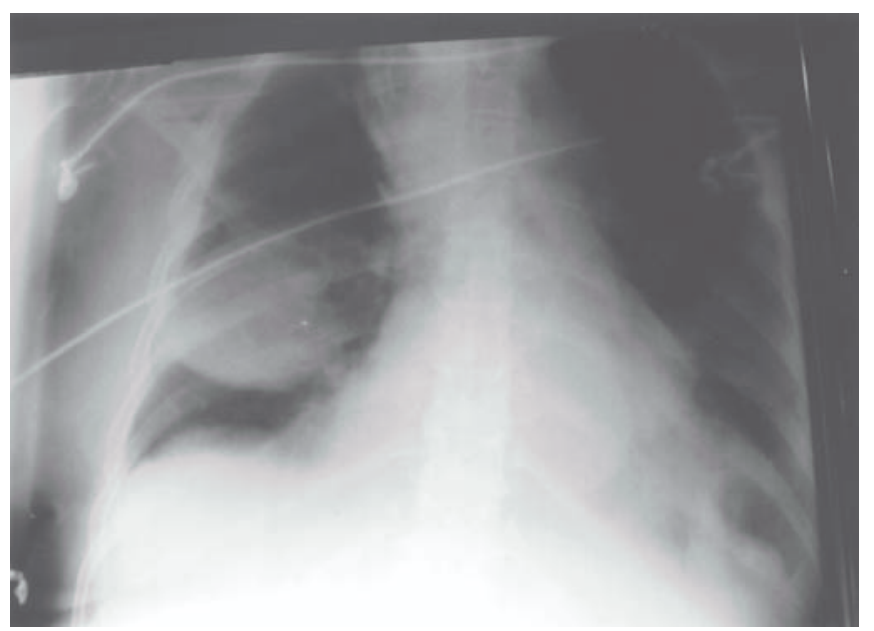

Figura 2 - O derrame no mediastino regrediu
No primeiro dia pós-operatório (PO), repetiu-se a radiografia do tórax, já com redução de $50 \%$ do quadro aproximadamente (figura 2), e boa evolução clínica. No segundo dia, a nova radiografia já estava praticamente normal (com exceção da área de derrame), a paciente estava bem clinicamente, sendo então extubada e mantida somente com máscara de oxigênio.

No terceiro dia PO, a paciente saiu da UTI, sendo encaminhada para a enfermaria, onde permaneceu internada e teve alta no dia seguinte, sem queixas respiratórias.

\section{DISCUSSÃO}

Cirurgia minimamente invasiva sugere baixa taxa de complicação ${ }^{(1)}$. Apesar disso, na última década, observou-se aumento exponencial no número de artroscopias de ombro realizadas e também na complexidade dos procedimentos, o que acarretou elevação correspondente na frequiência e tipos de complicações inerentes a tal procedimento.

Não obstante, as complicações respiratórias também são citadas como, por exemplo: compressão da traquéia ${ }^{(2)}$, pneumotórax $^{(3)}$, edema agudo de pulmão ${ }^{(4)}$, entre outros ${ }^{(5)}$.

Há somente um caso na literatura de compressão das vias aéreas por derrame no mediastino ${ }^{(6)}$. Estudos sistematizados investigando a real incidência de complicações respiratórias da artroscopia do ombro são escassos.

Todas essas complicações tiveram relação com a infusão de líquido durante a cirurgia e, mais particularmente, a pressão da bomba de infusão. Devido a tais fatores, vários autores preocupam-se com tal pressão, a fim de evitar esses danos respiratórios ${ }^{(7-9)}$. Em contrapartida, Hynson et al referem que a bomba, por si própria, não pode ser exclusivamente implicada nessa obstrução aérea, pois a alternativa utilizada, ou seja, mera elevação dos frascos de soro a um metro do ombro operado produzirá pressão de $73 \mathrm{mmHg}^{(6)}$.

Trabalhamos com pressão de $50 \mathrm{mmHg}$, mas, especificamente nessa paciente, usamos pressão em $60 \mathrm{mmHg}$ e fluxo de $120 \mathrm{~L} / \mathrm{min}$, pois havia sangramento difuso e de difícil controle. Acreditamos que esse valor não é uma pressão excessiva e, além do mais, o edema importante aconteceu com menos de uma hora de procedimento. Frisamos, então, a importância de observações freqüentes da região cervical e tórax do paciente pelo anestesista, como medida preventiva.

Concordamos também com Hynson et al, que afirmam que os procedimentos subacromiais como o que estávamos realizando podem produzir mais complicações por extravasamento de líquido do que os intra-articulares, pois a articulação é um compartimento fechado pela cápsula ${ }^{(6)}$. Noyes et al relata- 
ram também que uma parcela de líquido pode alcançar os tecidos moles pelos portais, aumentando o possível edema ${ }^{(10)}$.

Julgamos também que o fato de a paciente ser portadora de lúpus eritematoso sistêmico contribuiu para esse problema. Esses pacientes possuem tecido conjuntivo alterado pelo uso prolongado de corticóides ${ }^{(11)}$.

Com os avanços da artroscopia do ombro, a complexidade dos procedimentos aumenta e, com isso, o tempo de duração também se elevou. O potencial das complicações relacionadas ao extravasamento de líquido extra-articular, em consequiência, também aumentou, tanto quanto o tempo de duração da cirurgia. Em particular, o uso prolongado de altos níveis de pressão e fluxo de irrigação deverá elevar, substancialmente, o risco de edema das vias aéreas superiores.

Concordamos com De Wachter et al, que sugerem ser essencial a intubação endotraqueal nos pacientes que serão submetidos a esse tipo de procedimento, pois os mesmos demonstraram que a pressão paratraqueal pode aumentar muito, sendo uma ameaça à vida ${ }^{(12)}$. Até mesmo uma traqueostomia de emergência seria difícil, devido ao grande edema dessa região, após a cirurgia. Não obstante, devemos ter cuidado ao extubar esses pacientes, pois a reintubação é também complicada. É recomendável verificar, antes da retirada do tubo, se existe inspiração ao redor dele com o balonete vazio e com a extremidade do mesmo ocluído.

Em conclusão, a artroscopia de ombro é um procedimento seguro e efetivo. Entretanto, complicações graves e com risco de vida, como o extravasamento de líquido para o mediastino e derrame pleural, podem ocorrer. Observação constante do paciente e intubação endotraqueal devem fazer parte da rotina dessa cirurgia.

\section{REFERÊNCIAS}

1. Muller D, Landsiedl F. Arthroscopy of the shoulder joint: a minimal invasive and harmless procedure? [abstract]. Arthroscopy. 2000;16(4): 425.

2. Borgeat A, Bird P, Ekatodramis G, Dumont D. Tracheal compression caused by periarticular fluid accumulation: a rare complication of shoulder surgery. J Shoulder Elbow Surg. 2000;9(5):443-5.

3. Dietzel DP, Ciullo JV. Spontaneous pneumothorax after shoulder arthroscopy: a report of four cases. Arthroscopy. 1996;12(1):99-102.

4. Anderson AF, Alfrey D, Lipscomb AB Jr. Acute pulmonary edema, an unusual complication following arthroscopy: a report of three cases. Arthroscopy. 1990;6(3):235-7.

5. Lee HC, Dewan N, Crosby L. Subcutaneous emphysema, pneumomediastinum, and potentially life-threatening tension pneumothorax. Pulmonary complications from arthroscopic shoulder decompression. Chest. 1992;101(5):1265-7.

6. Hynson JM, Tung A, Guevara JE, Katz JA, Glick JM, Shapiro WA. Complete airway obstruction during arthroscopic shoulder surgery. Anesth Analg. 1993;76(4):875-8.

7. McFarland EG, O’Neill OR, Hsu CY. Complications of shoulder arthroscopy. J South Orthop Assoc. 1997;6(3):190-6.

8. Shaffer BS, Tibone JE. Arthroscopic shoulder instability surgery. Complications. Clin Sports Med. 1999;18(4):737-67.

9. Stanish WD, Peterson DC. Shoulder arthroscopy and nerve injury: pitfalls and prevention. Arthroscopy. 1995;11(4):458-66.

10. Noyes FR, Spievack ES. Extraarticular fluid dissection in tissues during arthroscopy. A report of clinical cases and a study of intraarticular and thigh pressures in cadavers. Am J Sports Med. 1982;10(6):346-51.

11. Cecil RL. Tratado de medicina interna. 19a.ed. Rio de Janeiro: Guanabara Koogan; 1993.

12. De Wachter J, Van Glabbeek F, van Riet R, Van Leemput W, Vermeyen K, Somville J. Surrounding soft tissue pressure during shoulder arthroscopy. Acta Orthop Belg. 2005;71(5):521-7. 